Macedonian was blockaded in New London for a year, and thence transferred to the lakes. After serving a year on the lakes in this ship, and in the frigate Mohawk, Dr. Harris was again ordcred to the Macedonian, Captain Jones, to form part of Decatur's squadron against Algiers. The Aigerine frigate, Mazouda, and a brig of war, were captured by Commodore Decatur. The Mazouda was unprovided with a surgeon, and had suffered greatly during the action. Dr. Harris was placed on board of her, where he had his hands full, with amputations and other operations. After cruising along the Barbary and other ports on the Mediterranean, he returned to the United States with the squadron in the autumn of 1815.

These three years of active service gave Dr. Harris an admirable opportunity of making himself a skilful operator. He had the qualities necessary to turn his advantages to account-judgment, coolness, readiness, and dexterity-and he came out of the war with an established reputation and solid experience.

Upon returning home, Dr. Harris was placed on furlough for a year; then ordered to the Guerrière at Boston, where he remained till 1817; and afterwards stationed at the hospital of the Navy Yard at Philadelphia. At this station he has been ever since fixed, with the exception of a short cruise to the West Indies in 1823. In this year, he was sent with Commodore Rogers at the head of a commission to examine into the condition of the seamen suffering from the yellow fever atKey West, and to report as to the elegibility of that port as a station for our squadrons. During his residence in Philadelphia, Dr. Harris has been employed in various capacities in the naval service. He was chosen to select the site for the Naval Asylum in this city and to superintend its erection; and has repeatedly served on the board to examine candidates for the medical corps.

With the advantage of an excellent reputation, Dr. Harris commenced the practice of lis profession in this city in 1817. His success has been brilliant. Two years ago, when he was compelled by ill health to relinquish active business, he was in the receipt of a professional income that has seldom been reached in Philadelphia. Dr. Harris possesses in an eminent degree those minor qualifications for professional success, without which the strongest combination of talent and knowledge is unavailing. To an agreeable address, a pleasant flow of conversation, and a cordiality of manner, the more attractive because felt to be sincere, he unites a ready command of resources, therapeutic and dietetic, and the happy capacity of almost endlessly varying them, and adapting them to the tastes of his patients.

Dr. Harris has been for a number of years a lecturer on surgery. In 1823, he formed one of a private association with Drs. Hewson, Meigs, and Bache, with whom he continued till 1826, when he was appointed to lecture on surgery in the Medical Institute. His courses in this school have been eminently popular. We have never heard a better practical lecturer. His style is familiar, sometimes conversational, and his matter has the great attraction of appearing to emanate more from his own experience than the gleanings of books. Dr. Harris has long been a champion of the non-specific doctrines of syphilis and of the anti-mer- curial treatment of this disease. He devotes a considerable portion of his lectures to this subject, and defends his views ably and ingeniously. Most of our readers will probably take issue with him on this point: at least, our own opinion is, that the mass of evidence, particularly the recent experiments by inoculation, tend to confirm the view of John Hunter " that the venercal disease arises from a poison, which is cabable again of producing a similar disease." Dr. Harris has had much reputation in the treatment of syphilitic affections. As he pursues a strictly antimercurial course, his success may fairly be adduced to show that the primary symptoms of the disease are very manageable without mercury. In 1826 , he published an elaborate memoir on this subject in the "North American Medical and Surgical Journal," which was extensively copied into the European journals.

Dr. Harris was for twelve years one of the surgeons to the Pennsylvania Hospital, having held the post from 1829 to 1841 , when he resigned from ill health. During this long clinical service, he has been distinguished for the success as well as the number of operations. In 1837 he excised the elbow-joint, for caries-the first time the operation was performed in this country. He amputated the tongue in two instances for hypertrophy. These cases were published in the "American Journal" for the years 1830 and 1837 , A series of excellent clinical lectures by Dr. Harris have appeared in this journal.

Dr. Harris has contributed a number of articles to different medical periodicals. In 1821 he published a paper on Metastasis in the "Medical Recorder," which, like the article on syphilis, went the rounds of the European journals. A life of Commodore Bainbridge, published in 1837, is extremely creditable to Dr. Harris's literary powers. This spirited sketch of the hero of the Java may fairly rank with any of our naval biographies.

For a year or two past the state of his health has forced Dr. Harris in a measure to retire from his professional avocations. We are sincerely glad to know that his strength is so far re-established as to permit him to give his summer course of lectures. No member of the profession can claim more of the regard and respect of his brethren, and his return to active duty will give general and real gratification.-Medical Examiner.

\section{THEORY OF DISEASE.}

By Justus Liebig, Ph. D.

(Concluded from $p$. 42.)

In regard to the nature and essence of the vital force, we can hardly deceive ourselves, when we reflect, that it behaves, in all its manifestations, exactly like other natural forces; that it is devoid of consciousness or of volition, and is subject to the action of a blister.

The nerves, which accomplish the voluntary and involuntary motions in the body, are, according to the preceding exposition, not the producers, but only the conductors of the vital force; they propagate motion, and behave towards other causes of motion, which in their manifestations are analogous to the vital force, towards a current of electricity, for example, in a precisely analogous manner. They permit the current 
to traverse them, and present, as conductors of electricity, all the phenomena which they exhibit as conductors of the vital force. In the present state of our knowledge, no one, probably, will imagine that electricity is to be considered as the cause of the phenomena of motion in the body; but still, the medical action of electricity, as well as that of a magnet, which, when placed in contact with the body, produces a current of electricity, cannot be denied. For to the existing force of motion or of disturbance there is added, in the electrical current, a new cause of motion and of change in form and structure, which cannot be considered as altogether inefficient.

Practical medicine, in many diseases, makes use of cold in a high!y rational manner, as a means of exalting and accelerating, in an unwonted degree, the change of matter. This occurs especially in certain morbid conditions in the substance of the centre of the apparatus of motion; when a glowing heat and a rapid current of blood towards the head point out an abnormal metamorphosis of the brain. When this condition continues beyond a certain time, experience teaches that all motions in the body cease. If the change of manner be chiefly confined to the brain, then the change of matter, the generation of force, diminishes in all other parts. By surrounding the head with ice, the temperature is lowered, but the cause of the liberation of heat continues; the metamorphosis, which decides the issue of the disease, is limited to a short period. We must not forget, that the ice melts and absorbs heat from the diseased part; that if the ice be removed before the completion of the metamorphosis, the temperature again rises; that far moret heat is re. moved by means of ice than if we were to surround the head with a bad conductor of heat. There has obviously been liberated in an equal time a far larger amount of heat than in the state of health; and this is only rendered possible by an increased supply of oxygen, which must have determined a more rapid change of matter.

The self-regulating steam-engines, in which, to produce a uniform motion, the human intellect has shown the most admirable acuteness and sagacity, furnish no unapt image of what occurs in the animal body.

Every one knows, that in the tube which conveys the steam to the cylinder where the piston-rod is to be raised, a stop-cock of peculiar construction is placed, through which all the steam must pass. By an arrangement connected with the regulating wheel, this stop-cock opens when the wheel moves slower, and closes more or less completely when the wheel moves faster than is required for a uniform motion. When it opens, more steam is admitted (more force), and the motion of the machine is accelerated. When it shuts, the steam is more or less cut off, the force acting on the piston-rod diminishes, the tension of the steam increases, and this tension is accumulated for subsequent use. The tension of the vapor, or the force, so to speak, is produced by change of matter, by the combustion of coals in the fire-place. The force increases (the amount of steam generated and its tension increase) with the temperature in the fire-place which depends on the supply of coals and of air. There are in these engines other arrangements, all intended for regulation. When the tension of steam in the boiler rises beyond a certain point, the passages for admission of air close themselves; the combustion is retarded, the supply of force (of steam) is diminished. When the engine goes slower, more steam is admitted to the cylinder, its tension diminishes, the air passages are opened, and the cause of disengagement of heat (or production of force) increases. Another arrangement supplies the fireplace incessantly with coals in proportion as they are wanted.

If we now lower the temperature at any part of the boiler, the tension within is diminished; this is immediately seen in the regulators of force, which act precisely as if we had removed from the boiler a certain quantity of steam (force). The regulator and the air passages open, and the machine supplies itself with more coals.

The body, in regard to the production of heat and of force, acts just like one of these machines. With the lowering of the external temperature, the respirations become deeper and more frequent; oxygen is supplied in greater quantity and of greater density; the change of matter is increased; and more food must be supplied, if the temperature of the body is to remain unchanged.

It is hardly necessary to mention, that in the body, the tension of vapor cannot, any more than an electrical current, be considered the cause of the production of force.

From the theory of disease developed in the preceeding pages, it follows obviously, that a diseased condition once established, in any part of the body, cannot be made to disappear by the chemical action of a remedy. A limit may be put by a remedy to an abnormal process of transformation; that process may be accelerated or retarded; but this alone does not restore the normal (healthy) condition.

The art of the physician consists in the knowledge of the means which enable him to exercise an influence on the duration of the disease; and in the removal of all disturbing causes, the action of which strengthens or increases that of the actual cause of disease.

It is only by a just application of its principles that any theory can produce really beneficial results. The very same method of cure may restore health in one individual, which, if applied to another, may prove fatal in its effects. Thus in certain inflammatory diseases, and in highly muscular subjects, the antiphlogistic treatment has a very high value; while in other cases blood-letting produces unfavorable results. The vivifying agency of the blood must ever continue to be the most important condition in the restoration of a disturbed equilibrium, which result is always dependant on the saving of time; and the blood, must, therefore, be considered and constantly kept in view, as the ultimate and most powerful cause of a lasting vital resistance, as well in the diseased as in the unaffected parts of the body.

It is obvious, moreover, that in all diseases where the formation of contagious matter and of exanthemata is accompanied by fever, two diseased conditions simultaneously exist, and two processes are simultaneously completed; and that the blood, as it were by reaction (i. e. fever), becomes a means of cure, as being the carrier of that substance (oxygen) without the aid of which the diseased products cannot be rendered harmless, destroyed, or expelled, from the body; a means of cure by which, in short, neutralisation or equilibrium is effected.-From Liebig's Animal Chemistry. 